\title{
Total Synthesis and Stereo-chemistry of Pinnatoxins B and C
}

\author{
Fumiyoshi Matsuura, Junliang Hao, Reinhard Reents, and Yoshito Kishi ${ }^{*}$ \\ Department of Chemistry and Chemical Biology, Harvard University, 12 Oxford Street, Cambridge, \\ Massachusetts 02138
}

\begin{abstract}
Pinnatoxins B and C were synthesized from diols (34 $R$ )-3b and (34 S)-3a, respectively, in a stereochemically controlled manner. Through extensive analysis of the ${ }^{1} \mathrm{H}$ NMR spectra of synthetic PnTXs B and C, the diagnostic NMR signals were first identified to differentiate (34 S)- and (34 $R$ )-diastereomers and then used to establish the C34 configuration of natural PnTXs B and C as 34 $S$ and $34 R$, respectively.
\end{abstract}

Food poisoning due to the ingestion of edible Pinna shellfish occurs frequently in the coastal regions of China and Japan. In 1995, Uemura and coworkers isolated pinnatoxin A (PnTX A), one of the major toxic principles responsible for the Pinna-shellfish poisoning. They elucidated its gross-structure and relative stereochemistry. ${ }^{1}$ Its unique molecular architecture and pronounced biological activity as a $\mathrm{Ca}^{2+}$-channel activator make PnTX A an intriguing synthetic target. ${ }^{2}$ We previously reported the total synthesis of PnTX A, thereby not only confirming its gross-structure and relative stereochemistry, but also establishing its absolute configuration (Figure 1). ${ }^{3}$

In 2001, Uemura and coworkers reported further progress in this area: (1) isolation of PnTXs $\mathrm{B}$ and $\mathrm{C}$ from Pinna muricata and (2) isolation of pteriatoxins A-C (PtTXs A-C) from Pteria penguin. ${ }^{4}$ Based on the similarity in the ${ }^{1} \mathrm{H}$ NMR characteristics of these new alkaloids with that of PnTX A, they suggested that PnTXs B/C and PtTXs A-C possess the gross structures shown in Figure 1, with the same stereochemistry at the macrocyclic core as that of PnTX A. In addition, through NOE studies, they proposed the absolute configuration at $\mathrm{C} 34$ of natural PnTXs B and C being $34 S$ and $34 R$, respectively. However, the C34 and C2' stereochemistry of PtTXs A-C were left unassigned. ${ }^{4}$

Our research interests in this area are two-fold: (1) to establish the complete stereochemistry of PnTXs B/C and PtTXs A-C and (2) to secure access to stereochemically homogeneous PnTXs and PtTXs, thus permitting unambiguous determination of their individual biological profiles. The naturally occurring PnTXs B/C and PtTXs B/C were isolated as a "HPLCinseparable" mixture. Therefore, the individual biological profile of each toxin was not characterized. ${ }^{4}$ In order to achieve our goals, we relied on organic synthesis and envisioned a unified synthetic strategy (Figure 2) to access each of the possible diastereomers in a stereochemically well-defined manner. This strategy will allow us to address the C34 and C2' configuration independently for all members of the PnTX/PtTX-class of marine toxins.

Recently, we have reported a total synthesis of PtTXs A-C and disclosed the experimental evidence to establish unambiguously their stereochemistry (Figure 1). ${ }^{5}$ In this letter, we report a total synthesis of PnTXs B and C from the intermediates used for the synthesis of PtTXs A$\mathrm{C}$ and present the evidence to confirm the stereochemistry proposed for PnTXs B/C by Uemura and coworkers. 
Our synthesis of PnTXs and PtTXs diverges after the intramolecular Diels-Alder reaction to form the carbo-macrocycle (Scheme 1). ${ }^{5}$ In order to establish the stereochemistry of the DielsAlder products, the major diastereomer was chemically correlated with $\mathbf{4}$ which is an advanced intermediate used in the previous PnTX A synthesis. ${ }^{3}$ Thus, the current work also constitutes a formal total synthesis of PnTX A.

We next focused on transformation of the C34/C35-diols 3a and $\mathbf{3 b}$ to the amino acid (Scheme 2). Through a two-step sequence, 3a was first converted to epoxide 5a. Based on the literature precedents, 6 we anticipated that ring-opening can be achieved preferentially at the secondary allylic position in an $\mathrm{S}_{\mathrm{N}} 2$ fashion. Indeed, treatment of $\mathbf{5 a}$ with $\mathrm{NaN}_{3}$ yielded azide $\mathbf{6} \mathbf{a}$ as a sole product. This result is a sharp contrast to the ring-opening behavior observed in the PtTX synthesis, where the epoxide-ring opening with $\mathrm{N}$-Boc-Cys $(\mathrm{SH})-\mathrm{OCHPh}$ took place at both the secondary and primary centers to furnish a 2:1 mixture of regioisomers. 5 Protected amino alcohol 7a, available in one step from $\mathbf{6 a}$, was transformed to $\mathbf{8 a}$ through oxidation and protection of the resultant carboxylic acid.

The particular combination of the two protecting groups at the amino acid moiety was chosen to ensure the carboxylic acid protecting group $\left(\mathrm{CHPh}_{2}\right)$ is cleaved prior to the amine protecting group (Boc). ${ }^{5}$ Prior to the formation of the 7 -membered imine, both silyl protecting groups at $\mathrm{C} 15$ and $\mathrm{C} 28$ were removed with HF.pyr. The final stage of the synthesis was completed in 3 steps, i.e., (1) Alloc group deprotection with $\mathrm{Pd}\left(\mathrm{PPh}_{3}\right)_{4}, \mathrm{AcOH}$ to give the corresponding amino-ketone, (2) imine-cyclization with 2,4,6- $(i \text { - } \mathrm{Pr})_{3} \mathrm{C}_{6} \mathrm{H}_{2} \mathrm{CO}_{2} \mathrm{H}-\mathrm{Et}_{3} \mathrm{~N}$ salt, ${ }^{5}$ and (3) removal of all the remaining protecting groups with TFA in $\mathrm{CH}_{2} \mathrm{Cl}_{2}$. Preparative HPLC allowed separation and isolation of synthetic (34R)-PnTX B/C (9a). Applying the same synthetic sequence on diol 3b, synthetic (34S)-PnTX B/C (9b) was obtained after HPLC purification.

With both synthetic PnTX C34-diastereomers in hand, we then analyzed their ${ }^{1} \mathrm{H}$ NMR profiles. ${ }^{1} \mathrm{H}$ NMR analysis first showed that the synthetic (34R)- and (34S)-PnTX B/C diastereomers thus obtained were cross-contaminated with the corresponding C34 diastereomer in an extent of 5 10\% (see colored arrows in Figure 3). Since 8a and $\mathbf{8 b}$ were diastereomerically homogeneous $\left({ }^{1} \mathrm{H}\right.$ NMR), the observed partial epimerization likely took place at the final deprotection.

Extensive ${ }^{1} \mathrm{H}$ NMR analysis revealed that the $\mathrm{C} 29-\mathrm{H}, \mathrm{C} 28-\mathrm{H}$, and $\mathrm{C} 36-\mathrm{H}$ are diagnostic to differentiate the (34S)-PnTX B/C diastereomer from the (34R)-PnTX B/C diastereomer (Figure $3)$. As observed in the PtTXs A-C series, $5 \mathrm{~b}$ the proton signals nearby the ionic centers were found to shift significantly depending on the sample preparation and concentration. However, the above-mentioned three characteristics were found to be inert, or at least to be not affected significantly. ${ }^{7}$ Focusing on these diagnostic signals, we then analyzed the NMR data reported for a ca. 1:1 mixture of the natural PnTXs B/C. This comparison allowed us to conclude that the C34 stereochemistry of PnTXs B and C corresponds to $34 S$ - and $34 R$-diastereomers, respectively. ${ }^{8}$ This conclusion coincides with the stereochemistry assigned through NOE studies by Uemura and coworkers. 9

In conclusion, we have completed the first total synthesis of PnTXs B and C in a stereochemically controlled manner and presented the experimental evidence to address the C34 stereochemistry. ${ }^{10}$ Combined with our recently reported synthesis of PtTXs A-C, ${ }^{5}$ we have completed a unified synthesis of the PnTX/PtTX-class of marine natural products, and unambiguously established their stereochemistry.

\section{Supplementary Material}

Refer to Web version on PubMed Central for supplementary material. 


\section{Acknowledgment}

We thank Professor D. Uemura, Nagoya University, Nagoya, Japan, for a generous gift of natural PnTXs B/C. Financial support from the National Institutes of Health (NS12108) is gratefully acknowledged. R.R. thanks Alexander von Humboldt Foundation for a Feodor Lynen postdoctoral fellowship.

\section{References}

1. (a) Uemura D, Chuo T, Haino T, Nagatsu A, Fukuzawa S, Zheng S, Chen H. J. Am. Chem. Soc 1995;117:1155. (b) Chuo T, Kamo O, Uemura D. Tetrahedron Lett 1996;37:4023. (c) Chou T, Haino T, Kuramoto M, Uemura D. Tetrahedron Lett 1996;37:4027.

2. For the synthetic work on PnTX, see: (a) Sakamoto S, Sakazaki H, Hagiwara K, Kamada K, Ishii K, Noda T, Inoue M, Hirama M. Hirama group. Angew. Chem. Int. Ed 2004;43:6505. Wang J, Sakamoto S, Kamada K, Nitta A, Noda T, Oguri H, Hirama M. Synlett 2003:891. Ishiwata A, Sakamoto S, Noda T, Hirama M. Synlett 1999:692. Nitta A, Ishiwata A, Noda T, Hirama M. Synlett 1999:695. Noda T, Ishiwata A, Uemura S, Sakamoto S, Hirama M. Synlett 1998:298. (b) Nakamura S, Inagaki J, Kudo M, Sugimoto T, Obara K, Nakajima M, Hashimoto S. Hashimoto group. Tetrahedron 2002;58:10353. Nakamura S, Inagaki J, Sugimoto T, Ura Y, Hashimoto S. Tetrahedron 2002;58:10375. Nakamura S, Inagaki J, Sugimoto T, Kudo M, Nakajima M, Hashimoto S. Org. Lett 2001;3:4075. [PubMed: 11735588] (c) Ishihara J, Horie M, Shimada Y, Tojo S, Murai A. Murai group. Synlett 2002:403. Ishihara J, Tojo S, Kamikawa A, Murai A. Chem. Commun 2001:1392. Sugimoto T, Ishihara J, Murai A. Synlett 1999:541. Ishihara J, Sugimoto T, Murai A. Synlett 1998:603. Sugimoto T, Ishihara J, Murai A. Tetrahedron Lett 1997;38:7379. (d) Suthers BD, Jacobs MF, Kitching W. Kitching group. Tetrahedron Lett 1998;39:2621. (e) Pelc MJ, Zakarian A. Zakarian group. Org. Lett 2005;7:1629. [PubMed: 15816769]

3. McCauley JA, Nagasawa K, Lander PA, Mischke SG, Semones MA, Kishi Y. J. Am. Chem. Soc 1998;120:7647.

4. (a) Takada N, Umemura N, Suenaga K, Chou T, Nagatsu A, Haino T, Yamada K, Uemura D. Tetrahedron Lett 2001;42:3491. (b) Takada N, Umemura N, Suenaga K, Uemura D. Tetrahedron Lett 2001;42:3495.

5. (a) Matsuura F, Peters R, Anada M, Harried SS, Hao J, Kishi Y. J. Am. Chem. Soc 2006;128:7463. [PubMed: 16756299] (b) Hao J, Matsuura F, Kishi Y, Kita M, Uemura D, Asai N, Iwashita T. J. Am. Chem. Soc 2006;128published online May 25, 2006, http://dx.doi.org/10.1021/ja061893j.

6. (a) Brittain J, Gareau Y. Tetrahedron Lett 1993;34:3363. (b) Yadav JS, Reddy BVS, Baishya G. Chem. Lett 2002:906. (c) Fan R-H, Hou X-L. J. Org. Chem 2003;68:726. [PubMed: 12558391]

7. Although $\mathrm{C} 32-\mathrm{H}$ and $\mathrm{C} 34-\mathrm{H}$ initially appeared to be useful diagnostic signals for comparison purposes, we found that their chemical shifts vary significantly depending on the sample preparation and concentration. Thus, unless these spectra were recorded under identical conditions, they cannot be used to differentiate PnTXs B and C. However, we did observe that the relative chemical shifts of C32-H for PnTXs B and C remain unchanged under various conditions. For details, see Supporting Information.

8. We recorded a ${ }^{1} \mathrm{H}$ NMR spectrum of the synthetic PnTX C (contaminated with 5 10\% of PnTX B) doped with a small amount of natural PnTX B/C (ca. 1:1 mixture) and observed no signals doubled, except that the intensity of C32-H, C29-H, C28-H, and C37-H peaks, corresponding to the contaminated PnTX B, increased noticeably. For details, see Supporting Information.

9. Upon comparison of ${ }^{1} \mathrm{H}$ NMR spectra between the synthetic and natural samples, we found that the chemical shifts for the $\mathrm{C} 37$ methyl groups were different from the originally reported figures and should be $\delta=1.04 \mathrm{ppm}$ for PnTX B and $\delta=1.05 \mathrm{ppm}$ for PnTX C. For details, see Supporting Information.

10. Preliminary mice acute toxicity assays showed that both synthetic PnTXs B and C exhibit comparable activity at the dose of $0.1 \mathrm{mg} / \mathrm{kg}$. We thank Professor D. Uemura and Dr. M. Kita at Nagoya University, Nagoya, Japan, for the assays. 


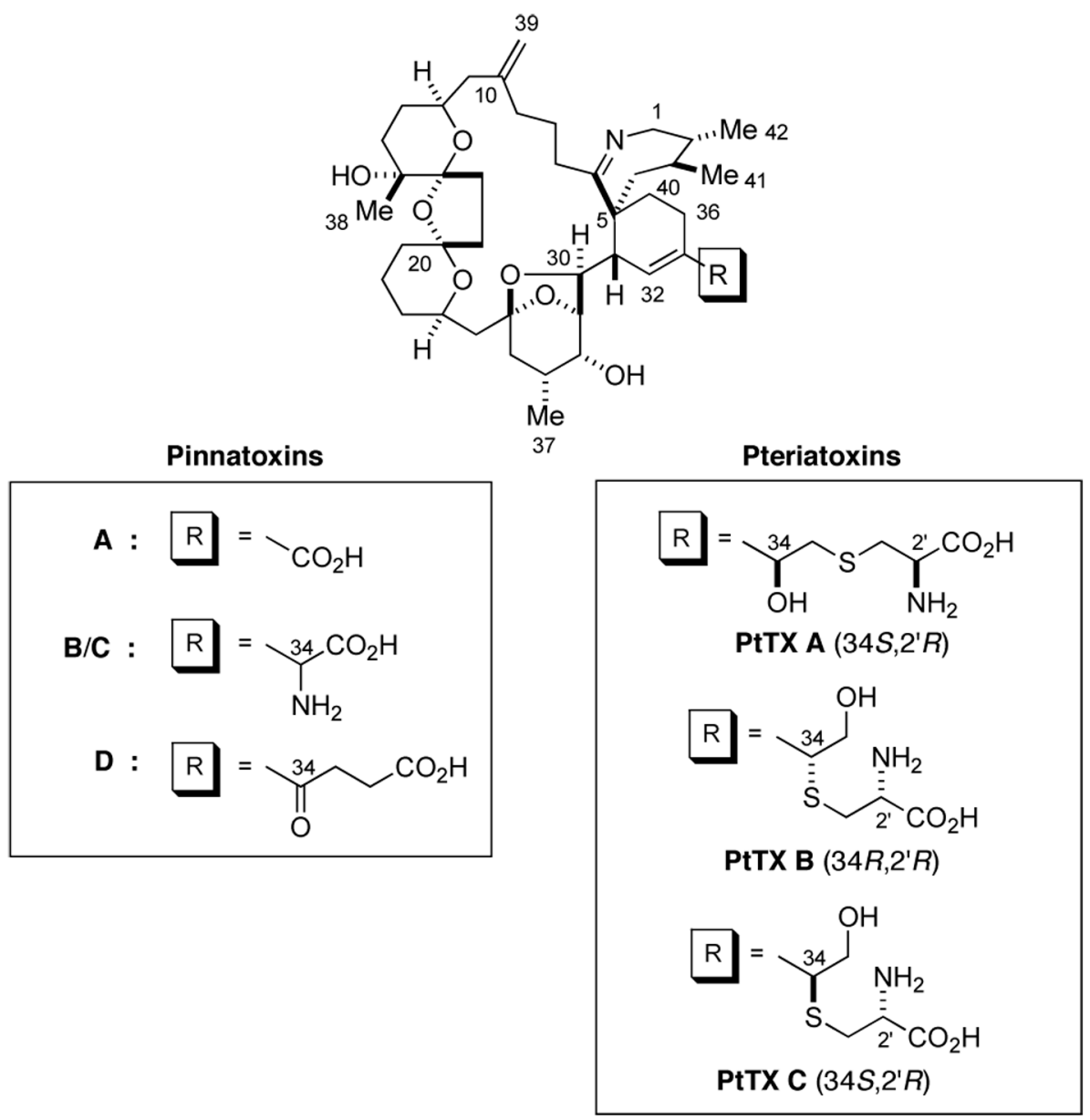

Figure 1.

Structures of PnTXs and PtTXs. 


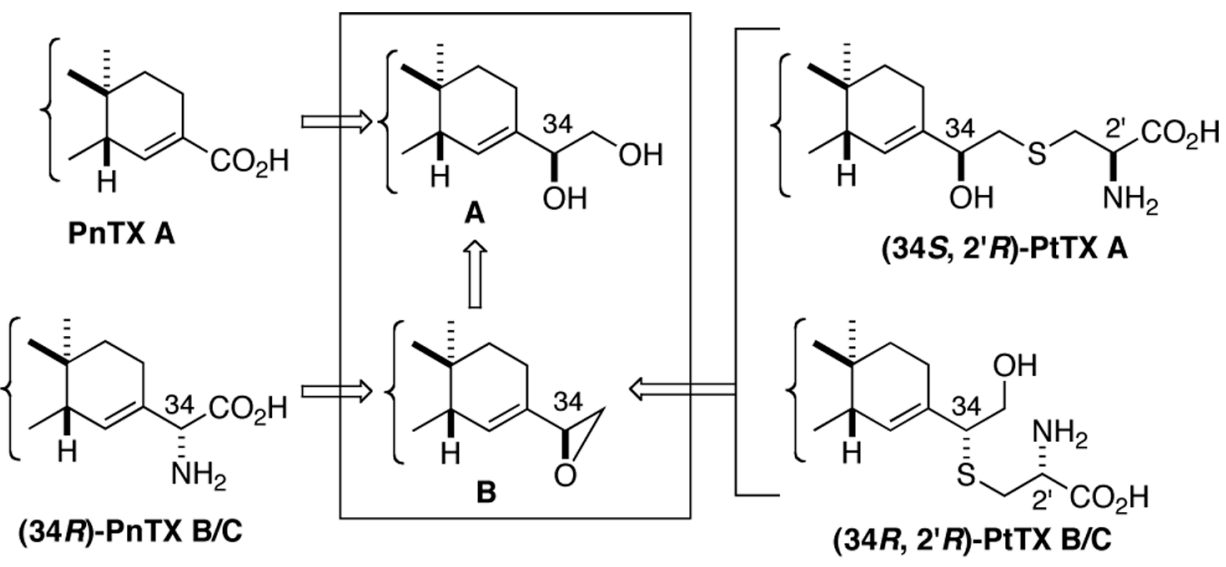

Figure 2.

Unified Total Synthesis of the PnTX/PtTX-Class of Marine Natural Products. 

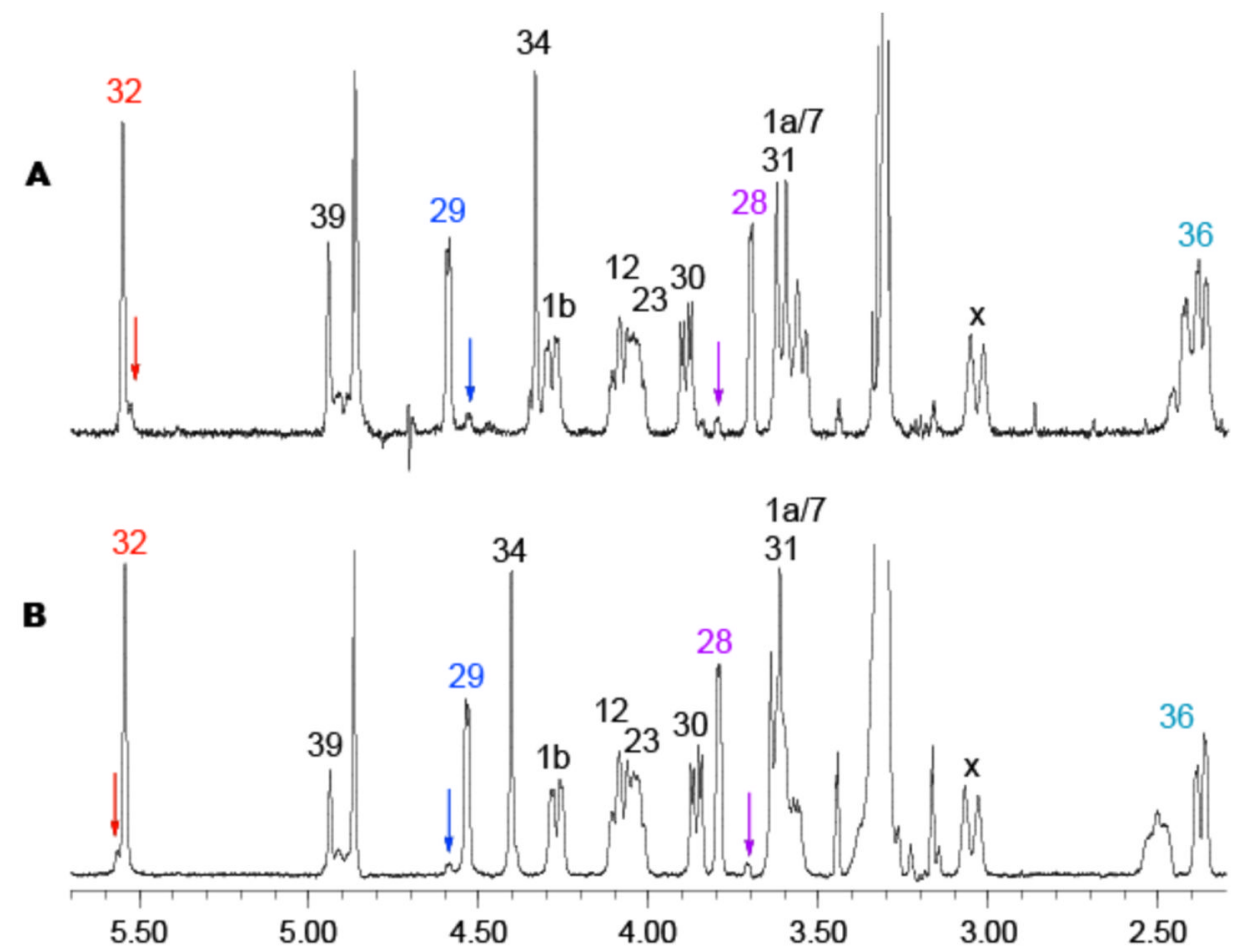

Figure 3.

Partial ${ }^{1} \mathrm{H}$ NMR spectra $\left(500 \mathrm{MHz}, \mathrm{CD}_{3} \mathrm{OD}\right)$ of the synthetic (34S)-stereoisomer (Panel A) and (34R)-stereoisomer (Panel B). 


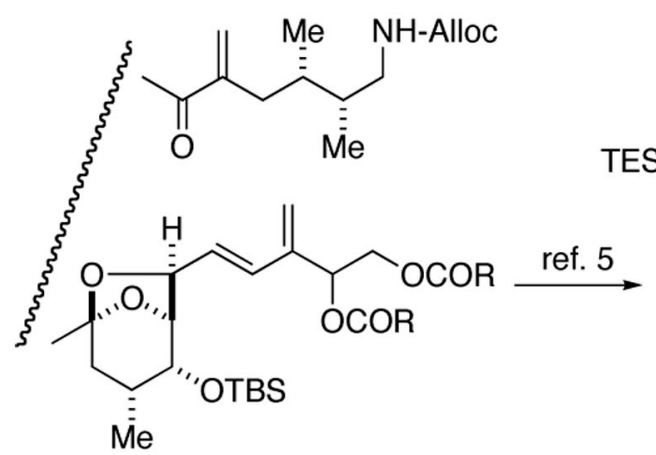

(34S)-1: $\mathrm{R}=(p-\mathrm{MeO}) \mathrm{Bz}$ (34R)-2: $R=A C$

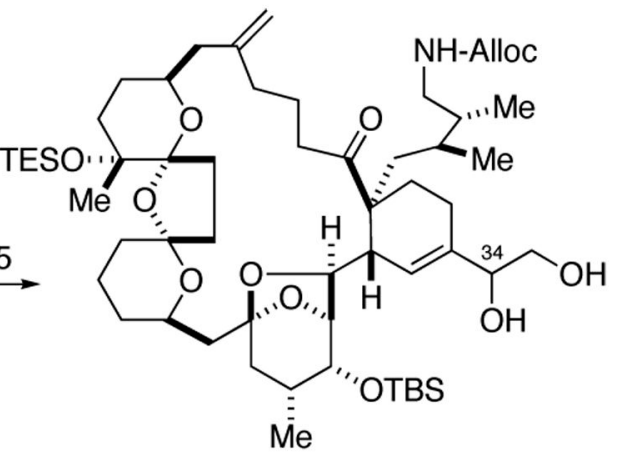

(34S)-3a

(34R)-3b

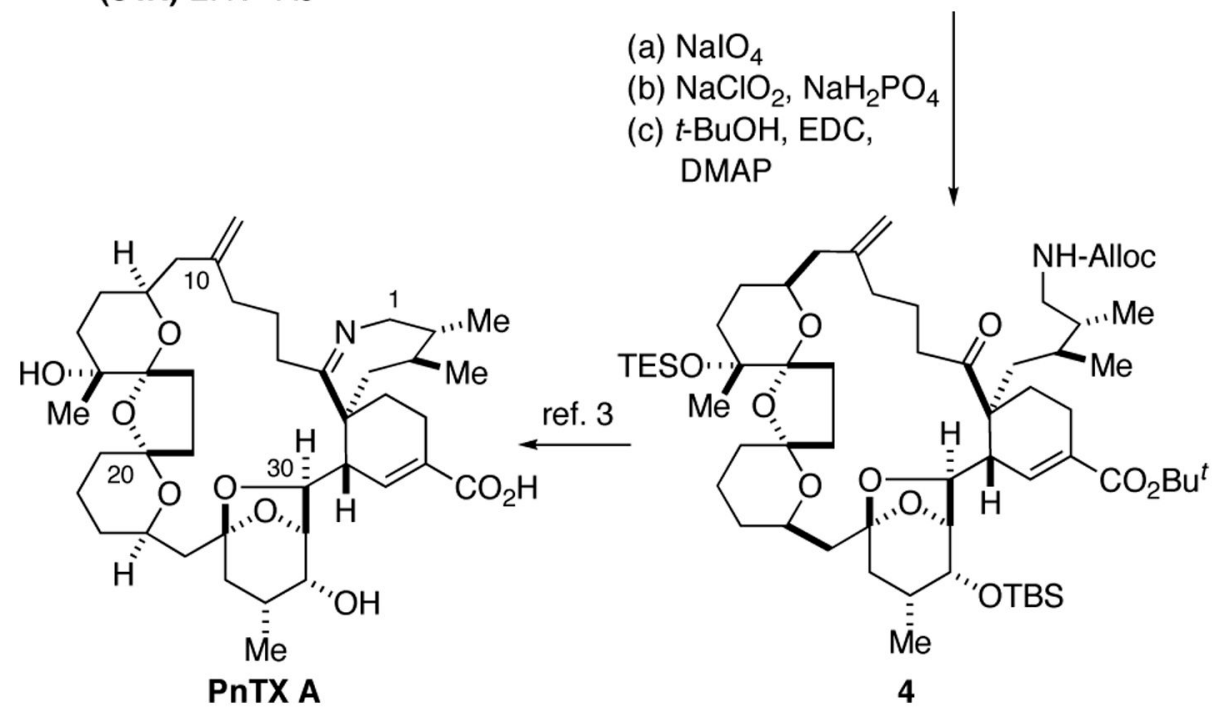

Scheme 1. 


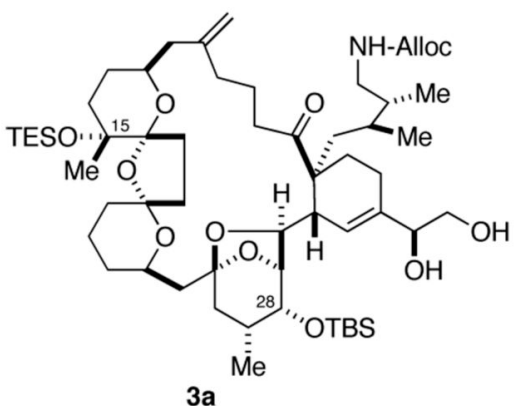

$3 a$

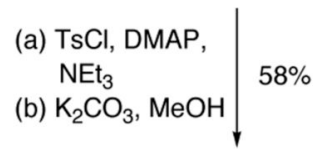<smiles>[CH2]C(=O)[C@@]1([CH2])CCC(C2CO2)=C[C@H]1[CH2]</smiles>

$5 a$

$\mathrm{NaN}_{3} \downarrow 96 \%$

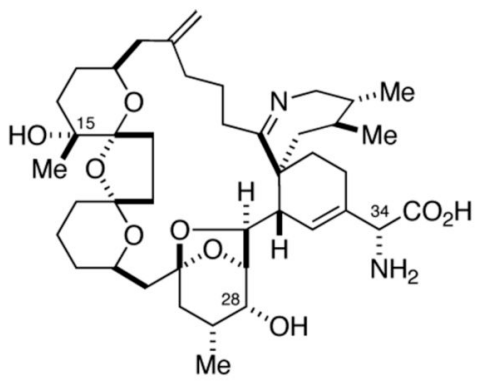

9a $=$ PnTX C

(34R)-Diastereomer

(a) HF•pyr, pyr

(b) $\mathrm{Pd}\left(\mathrm{PPh}_{3}\right)_{4}, \mathrm{AcOH}$

(c) 2,4,6-(i-Pr) ${ }_{3} \mathrm{C}_{6} \mathrm{H}_{2}-$ $-\mathrm{CO}_{2} \mathrm{H}-\mathrm{Et}_{3} \mathrm{~N}$, xylene, $80^{\circ} \mathrm{C}$

(d) TFA, $\mathrm{CH}_{2} \mathrm{Cl}_{2}$

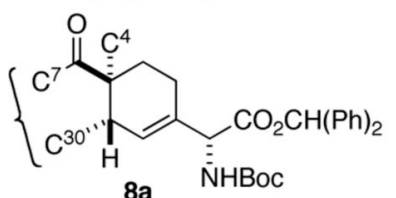

(a) Dess-Martin [O]

(b) $\mathrm{NaClO}_{2}$

(c) $\mathrm{Ph}_{2} \mathrm{C}=\mathrm{N}_{2}$

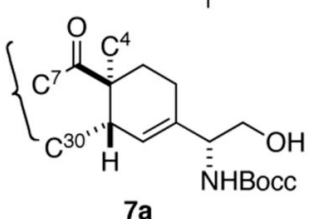

$7 a$

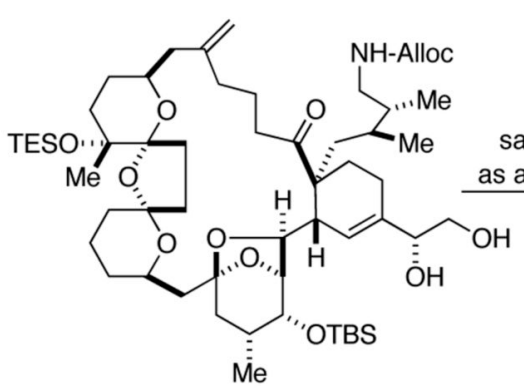

3b
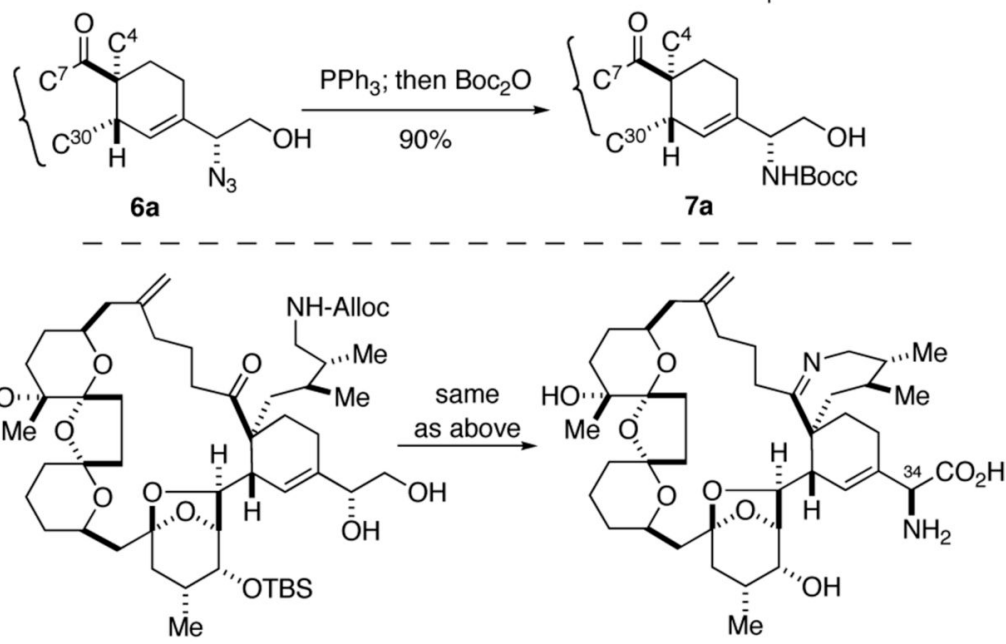

$9 \mathrm{~b}=\mathrm{PnTX} \mathrm{B}$

(34S)-Diastereomer

Scheme 2. 